Subjects and Objects: A Semantic Account of Yurakaré Argument Structure Author(s): Rik van Gijn

Reviewed work(s):

Source: International Journal of American Linguistics, Vol. 77, No. 4 (October 2011), pp. 595621

Published by: The University of Chicago Press

Stable URL: http://www.jstor.org/stable/10.1086/662158

Accessed: $1 7 \longdiv { / 1 1 / 2 0 1 1 0 2 : 3 3 }$

Your use of the JSTOR archive indicates your acceptance of the Terms \& Conditions of Use, available at http://www.jstor.org/page/info/about/policies/terms.jsp

JSTOR is a not-for-profit service that helps scholars, researchers, and students discover, use, and build upon a wide range of content in a trusted digital archive. We use information technology and tools to increase productivity and facilitate new forms of scholarship. For more information about JSTOR, please contact support@jstor.org. 


\title{
SUBJECTS AND OBJECTS: A SEMANTIC ACCOUNT OF YURAKARÉ ARGUMENT STRUCTURE ${ }^{1}$
}

\author{
RIK VAN GIJN \\ Max Planck Institute for Psycholinguistics and Radboud University NiJMEgen
}

\begin{abstract}
Yurakaré (unclassified, central Bolivia) marks core arguments on the verb by means of pronominal affixes. Subjects are suffixed, objects are prefixed. There are six types of head-marked objects in Yurakaré, each with its own morphosyntactic and semantic properties. Distributional patterns suggest that the six objects can be divided into two larger groups reminiscent of the typologically recognized direct vs. indirect object distinction. This paper looks at the interaction of this complex system of participant marking and verbal semantics. By investigating the participant-marking patterns of nine verb classes (four representing a gradual decrease of patienthood of the $\mathrm{P}$ participant, five a gradual decrease of agentivity of the A participant), I come to the conclusion that grammatical roles in Yurakaré can be defined semantically, and case frames are to a high degree determined by verbal semantics.
\end{abstract}

[KEYwORDS: Yurakaré, grammatical relations, semantic roles, verbal semantics]

1. Introduction. Yurakaré, an unclassified language spoken on the fringes of the central Bolivian lowland area, displays a nominative-accusative alignment pattern, encoded by means of cross-referencing affixes on the verb. Subjects are suffixed, objects are prefixed. ${ }^{2}$ The NPs corresponding to the pronominal affixes do not have to be expressed. When they are, there is no fixed order of subject and object that could further indicate the grammatical role of the participant.

There is an elaborate system of objects in Yurakaré. Six different types can be distinguished, each with its own morphosyntax and semantics. Five

${ }^{1}$ I thank the people of La Misión, Tacuaral, Nueva Canaan, Loma del Masí, Nueva Lacea, and Tres de Mayo for sharing their knowledge of Yurakaré with me. I would also like to thank Helen de Hoop, Antoine Guillaume, Françoise Rose, and an anonymous reviewer for comments on earlier drafts of this paper. Remaining errors are mine.

2 The following abbreviations are used: 1 first person, 2 second person, 3 third person, ABL ablative, ADJ adjectivizer, BEN benefactive, BND bounded, CNTR contrastive, COM comitative, DEL delimiter, DEM demonstrative, DET determination, DIR direction, DO direct object, DT different topic, DSC discontinuative, DST distributive, FUT future, GOA goal, ICO involuntary comitative, IMP imperative, INC incompletive, INS instrument, LOC locative, MAL malefactive, MID middle voice, NEG negation, PL plural, PROH prohibitive, PS possessive, TOP topic, SG singular, ST same topic, vCO voluntary comitative, wH question word. Two different meanings for one form are separated by a semicolon (;) if the form corresponds to one of two possible interpretations. A period (.) is used between two meaning components of portmanteau forms; and a colon (:) is used for two fused forms, each with its own meaning.

[IJAL vol. 77, no. 4, October 2011, pp. 595-621]

(C) 2011 by The University of Chicago. All rights reserved.

0020-7071/2011/7704-0008\$10.00 
of these six objects might be analyzed as applicative objects, but, as I argue below, the distinction between applied and non-applied objects is not very clear-cut, and it is questionable if this is a useful distinction for Yurakaré.

In this paper, I look at non-canonical case patterns in Yurakaré, which are defined as two-participant events where either the patient-like $(\mathrm{P})$ participant is not encoded as a direct object or the agent-like (A) participant is not encoded as a subject. I argue for a semantic approach to Yurakaré argument structure, where the choice of argument encoding is determined by verbal semantics and a concomitant decrease in affectedness of the P-participant or a decrease in agentivity of the A-participant.

I begin with a short overview of the language and its speakers (2). In 3, I discuss the theoretical ideas underlying the paper. Section $\mathbf{4}$ is a descriptive account of the head-marking strategies for marking participants and provides an analysis of the system of argument head-marking. Section $\mathbf{5}$ is devoted to the role of verbal semantics in the choice of argument encoding. In $\mathbf{6}, \mathbf{I}$ present my conclusions.

2. The language. Yurakaré is an unclassified language spoken in Central Bolivia in a sizable area near the foothills of the Andes. It has an estimated 2,500 speakers, living in dispersed, small communities along the many rivers in the area. The language is endangered because the youngest speakers often have at best a passive knowledge of the language.

The oldest language source available is Adam (1893), a grammar and vocabulary of the language based on field notes of Franciscan Father LaCueva, who stayed with the Yurakaré from the end of the eighteenth to the beginning of the nineteenth century. Lassinger (1915) contains a short grammar, based on Latin. The New Tribes Mission (henceforth NTM) developed a short grammar in English (n.d.), for the linguistic training of missionary workers. NTM (1991) is a large Yurakaré-Spanish, Spanish-Yurakaré vocabulary. Another vocabulary is Ribera, Rocha, and Rivero (1991), also Yurakaré-Spanish and Spanish-Yurakaré. NTM (1991) and Ribera, Rocha, and Rivero (1991) are complementary in the sense that they are based primarily on data from two different regions. Van Gijn (2006) is a grammatical description of Yurakaré. Finally, annotated primary Yurakaré material is available at <www.mpi.nl/ DOBES/projects/yurakar>, a database created for the DoBeS (Documentation Bedrohter Sprachen) foundation.

A few proposals linking Yurakaré to larger genetic units have been made, which generally contradict each other, and none of them has led to any consensus. Swadesh (1962) places Yurakaré in the Macro-Quechuan group, with Tacapano (= Pano-Tacanan) and Sonchon (Mosetén, Chon, Hongote) as its closest affiliates. Suárez (1974) concludes that the groupings proposed by Swadesh actually form a genetic unit. Greenberg (1987) classifies Yurakaré as an Equatorial language (with, e.g., Macro-Arawakan and Zamucoan but 
rather far removed from Quechuan). These different proposals have been largely dismissed on methodological grounds, and because some of them contain many errors in the data.

Yurakaré is an agglutinating polysynthetic language. It does not allow nominal incorporation, but core arguments are obligatorily marked on the verb by means of pronominal affixes. Yurakaré is predominantly head-marking: core grammatical relations are marked on the verb and possession is marked on the possessum. The verb in general is the main locus of morphological complexity. As is argued in this paper, the encoding of core arguments is to a large degree dependent on the semantics of the verb, but Yurakaré can be classified as an accusative language. Syntactically, Yurakaré is basically $\mathrm{V}$-initial, with relatively free constituent order. The order of adjectives and nouns is variable; the language has postpositions but no prepositions.

The writing system of Yurakaré used in this paper follows the official writing system which was established at a meeting held in Santa Cruz, Bolivia, July 25-26, 2007. ${ }^{3}$

The data in this paper are based on several fieldtrips that I made, first (2001-2005) under the auspices of the Spinoza Project, Lexicon and Syntax (Radboud University Nijmegen), then (2006-present) for the aforementioned DoBeS documentation project at the Max Planck Institute Nijmegen.

3. Theoretical preliminaries. As I discuss case patterns, it is important to specify what I mean by case. The definition of case that I use is broader than the one used by some authors. A more stringent definition of case is given by Blake (2001:1): "A system of marking dependent nouns for the type of relationship they bear to their heads." In this view, case is seen as a purely dependent-marking strategy. Other authors have a wider definition of case, including head-marking strategies as well. Butt (2006:6), for instance, mentions that "as case-bearing affixes are often historically derived from the incorporation of pronouns, the two cross-referencing strategies [head- and dependent-marking-RvG] could in fact reasonably be taken as instances of essentially the same phenomenon: case." For Yurakaré, I will follow this latter, wider definition, especially given the fact that the forms of the verbal affixes often formally correspond to forms of the free pronouns.

This paper is based on three different ideas about case marking and argument structure. The first is put forward by, among others, Croft (2001:170): "Syntactic roles define regions in conceptual space that represent semantically

\footnotetext{
3 The Yurakaré phoneme inventory is given below, with the practical orthography specified in angle brackets where different from IPA conventions. Yurakaré vowel phonemes are $i, \dot{t}<\dot{\mathrm{u}}>$, $u, e, o, a<\ddot{\mathrm{e}}>, a$. Consonants are $p, t, t \int<\mathrm{ch}>, k, ?<'>, b, d, d^{j}<\mathrm{dy}>, s, \int<\mathrm{sh}>, h<\mathrm{j}>, f<\mathrm{r}>, m$, $n, n<\tilde{\mathrm{n}}>, l, w, y$. Geminate consonants are represented by doubling the consonant, except for geminate $/ \mathrm{n} /, / \mathrm{t} \mathrm{J} /$, and $/ \mathrm{d}^{\mathrm{j}} /$, which are represented by $n \tilde{n}$, $t c h$, and $d d y$, respectively.
} 
related groupings of participant roles of events." Croft argues that syntactic roles can, and in fact should, be defined semantically rather than syntactically, i.e., cases have semantic coherence. Departing from this idea, I give a semantic account of the different head-marked syntactic roles of Yurakaré in $\mathbf{4}$ below.

The second idea comes from Malchukov (2005). It is an elaboration of earlier work on transitivity and case frames by, among others, Hopper and Thompson (1980) and Tsunoda (1981). Malchukov claims that "a decrease in affectedness on the part of $\mathrm{O}$ [and a]. . reduction in agentivity on the part of A. . . lead into the domain of agent-like and patient-like intransitives, respectively" (2005:111). In his paper, Malchukov looks at transitivity splits from the perspective of verbal semantics and produces a semantic map which displays three basic routes (two of which are represented in the quotation given above) in which verbs or constructions can represent different points on a scale going from transitive-like to intransitive-like. I come back to Malchukov's map in $\mathbf{5}$ below.

The third idea is from Lehmann, Shin, and Verhoeven (2000). In their paper, Lehmann, Shin, and Verhoeven set up a typology of person-prominent vs. relation-prominent languages, based on whether languages, in assigning a syntactic role to participants in a given event, give prominence to semantic characteristics of the argument related to animacy or to its semantic relation to the verb. Person prominence and relation prominence can be described as follows:

PERSON PROMINENCE: In assigning a grammatical role, a language gives prominence to characteristics of participants, e.g., animacy, salience, referentiality.

RELATION PROMINENCE: In assigning a grammatical role, a language gives prominence to the semantics of the relation between the verb and a participant.

This typology is based on the combination of two hierarchies: the participant features hierarchy and the syntactic functions hierarchy:

(1) PARTicipant FEATURES HIERARCHY speech-act participants $>$ human $>$ animate $>$ inanimate substance $>$ location $>$ proposition

(2) SYNTACTIC FUNCTIONS HIERARCHY

subject $>$ object $>$ indirect complement $>$ adjunct $>$ adnominal function $>$ syntactic function in embedded clause

Person-prominent languages tend to map participants higher on the participant features hierarchy onto functions higher on the syntactic functions hierarchy, irrespective of the semantics of the relation between the verb and a participant. Relation-prominent languages assign grammatical roles according to the 
semantic relation of the participant to the verb, regardless of the participant features.

I show that these three ideas taken together can explain the distribution of case marking in Yurakaré to a large degree.

4. Participant encoding in Yurakaré. Yurakaré has an accusative alignment pattern, in which subjects of intransitive clauses (S) are encoded in the same way as subjects of transitive clauses (A), and different from objects of transitive clauses $(\mathrm{P})$, as illustrated in (3):

(3a) mi-bobo-y

2sG.DO-hit;kill-1sG.S

'I hit you'.

(3b) mala-y

go.sG-1SG.S

'I went (away)'.

Arguments are indexed on the verb. Overt NPs or free pronouns may be expressed but need not be. Subjects are suffixed, objects are prefixed. These affixes are partly related to the forms of the free pronouns, as shown in (4).

(4) Object Subject Free Pronouns

$\begin{array}{llll}t i- & -y & \text { sё } & 1 \mathrm{SG} \\ m i- & -m & \text { mëe } & 2 \mathrm{SG} \\ k a- & -\emptyset 4 & \text { ana/ati/naa (demonstrative pronouns) } & 3 \mathrm{SG} \\ t a- & -t u & \text { tuwa } & 1 \mathrm{PL} \\ p a- & -p & \text { paa } & 2 \mathrm{PL} \\ m a- & -\emptyset=w & \text { ana }=w / a t i=w / n a a=w \text { (demonstrative pronouns) } & 3 \mathrm{PL}\end{array}$

The free pronouns for second-person singular, first-person plural, and secondperson plural are clearly related formally to the bound forms, both in the subject and in the object paradigms. ${ }^{5}$ As for the third persons, they are not formally related to the demonstratives ( $a n a$, ati, and naa), but the system of singular $(\emptyset)$ versus plural $(=w)$ marking on the demonstratives is maintained in the subject paradigm.

As I discuss at more length below, there are six different functional types of objects that, even though their paradigms are all related to the object paradigm

${ }^{4}$ I consider the third-person subject marker to be a zero element that is actually present. The argument here is that the nominal plural marker $=w$, used to mark third-person plural, needs a pronominal element over which to have scope. Therefore, the zero element appears in the examples with the gloss ' 3 ' for third person.

5 Phonetically, the form of the free pronoun for first-person singular is pronounced [ ${ }^{\mathrm{t}} \mathrm{s}$ ], with a small $t$-onset. This also makes its formal relation to the bound object form $t i$ - more likely. 
in (4), are each marked in different ways. Deviations from the basic paradigm are pointed out when relevant.

4.1. Subjects. At first glance, subjects in Yurakaré seem to be quite flexible regarding which kind of semantic roles they can encode. Of course, subjects can encode agents:
(5) $s \ddot{e}=j a$
bobo-y
ti-tiba
I=TOP hit;kill-1sG.S
1sG.PS-pet
'I hit my pet'.

However, subjects can also encode less agent-like semantic roles:
(6a) yujshë=ja bobo- $\emptyset$ yee wind=TOP hit;kill-3.s woman
(force)
'The tornado killed the woman'.
(6b) mitchi $=w$ peta- $\emptyset=w \quad$ elle $=y$
cat $=$ PL lie.PL-3.S=PL ground $=$ LOC
(theme)
'The cats lie on the ground'.
(6c) $s \ddot{e}=j a$ adyindye-y
$\mathrm{I}=$ TOP $\quad$ sad-1 1 SG.S
(experiencer)
'I am sad'.

I return to the semantics of subjects in Yurakaré in $\mathbf{5 . 2}$ below and show that the subject category has its semantic limits after all.

4.2. Objects. There are different ways of looking at objects in Yurakaré. One can make a distinction between the direct object, on the one hand, and five applicative objects (malefactive, beneficiary, goal, involuntary comitative, and voluntary comitative), on the other. Alternatively, Yurakaré can be regarded as having six different but equivalent types of objects. In this paper, I consider the objects of Yurakaré in the latter way and argue for this position below.

An applicative construction can be defined as follows: "a means some languages have for structuring clauses which allow the coding of a thematically peripheral argument or adjunct as a core-object argument. Such constructions are signaled by overt verbal morphology" (Petersen 2007:1). This definition gives us three diagnostics to differentiate direct objects from applied objects: (1) lexical requirement: direct objects are required by the argument structure of a verb, thematically peripheral arguments (even in the form of applied objects) are not; (2) alternation: applied objects are objects "promoted"' to core-argument status; this implies that there are alternative ways to express an utterance, where the participant is not expressed as a core argument; and (3) verbal morphology: applied objects are signaled by overt verbal morphology. 
In Yurakaré, all three diagnostics seem to play a role, but all three of them are also problematic. First, for the lexical requirement, verbs in Yurakaré can be classified for transitivity, i.e., there are verbs that require a direct object and verbs that do not, and only a few verbs can be either transitive or intransitive. ${ }^{6}$

On the other hand, there are verbs that require non-direct, head-marked objects (that might be called applicative) in their argument structure, such as:

(7a) ti-ma-n-kaya-ma

1SG-3PL.DO-BEN-give-IMP.SG

'Give them to me!'

(7b) të-yuda-ma

1sG.VCO-help-IMP.SG

'Help me!'

(7c) mi-la-ñole-y

2SG-MAL-desire-1SG.S

'I desire you'.

The verb kaya 'give' is ditransitive: it requires, in addition to the subject, two other head-marked objects: a direct object and a beneficiary object. The person prefix of the beneficiary participant is separated from its associated verbal marker $n$ - by the direct object person marker. I come back to issues of linear order in $\mathbf{4 . 3}$ below. The verb ayuda 'help' is a loanword from Spanish that obligatorily takes a voluntary comitative argument. The predicate ñole 'desire' obligatorily takes a malefactive object.

In short, the criterion of lexical requirement is problematic on two counts: there are verbs that do not require but that do allow direct objects (although very few); a more serious consideration is the fact that there are verbs that require non-direct, head-marked objects.

The second criterion, alternation, is also problematic in Yurakaré. The promotion of a peripheral argument to a core-object argument can best be illustrated with the involuntary and voluntary comitative. There is a competing postposition =tina that marks comitative. This enclitic attaches to the last element of the noun phrase and collapses the distinction made between voluntary and involuntary. In (8), two pairs of sentences are given to illustrate the "upgrading" of the peripheral participant marked with =tina to core-argument status:

${ }^{6}$ I have in fact found only two ambitransitive verbs so far: daja 'hang' and pëjta 'plant/be planted'. Although further research may reveal more ambitransitive verbs, I think it is safe to say that there are very few in Yurakaré. 
(8a)
уира- $\emptyset$

$$
\text { a-ballata=tina }
$$
3SG.PS-seeds $=\mathrm{COM}$

'He went in with his plant seeds'.

(8b) ka-yupa- $\emptyset \quad$ a-ballata

3sG.ICO-enter.SG-3.s 3sG.PS-seeds

'He went in with his plant seeds'.

(8c) dula- $\emptyset \quad$ a-bisi=tina

do;make-3.s 3sG.PS-brother=COM

'He made it with his brother'.

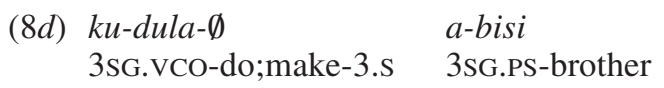

'He made it with his brother'.

In general, it can be said that more topical participants are more likely to be expressed with a person marker on the verb (see Van Gijn 2005).

For the other head-marked objects, the story is more complicated in the sense that for most constructions involving head-marked objects, there is no dependent-marked alternative. In very rough terms, the following correspondences can be said to exist between the three remaining head-marked objects and postpositional enclitics:
(9) Malefactive object Goal object
Ablative postposition
Benefactive object
Directional postposition
Directional postposition

However, in most circumstances, the meaning of the head-marked construction is not equivalent to the meaning of the postpositional enclitics, so that there is rarely a choice between the head-marked construction and the postposition. For one thing, the head-marked objects reflect a higher degree of involvement than is the case in the postpositional reading. Consider the following examples:
(10a) pelota $=$ chi mala-y
ball=DIR go.sG-1sG.S
'I went to the ball'.
(10b) pelota ka-y-mala-y
ball 3sG-GOA-go.sG-1sG.S
'I went for the ball/to get the ball'.

In $(10 b)$, the ball, marked on the verb by $k a-y$-, is more central to the action than in $(10 a)$, where it is not head-marked, in that it changes the basic meaning of the predicate (an equivalent change in interpretation would be English go to fetch). 
The examples (11a) and (11b) illustrate a difference in affectedness and empathy between a dependent-marked (11a) and a head-marked (11b) object:

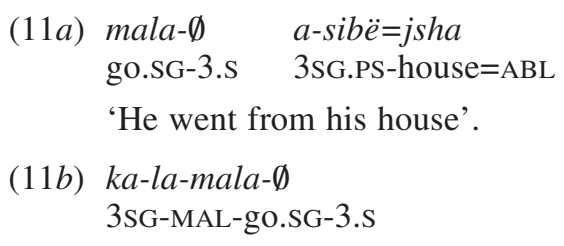

'He went away from him (left him alone)'.

The inanimate participant sibb $\ddot{e}^{7}$ 'house' in (11a) cannot be head-marked, and the animate, pronominal object of $(11 b)$ cannot be dependent-marked. This is illustrative of an almost grammaticalized animacy split for malefactive and beneficiary objects in Yurakaré. In my view, this has to do with the empathy principle (Kuno 1976) which states that speakers empathize more with animate participants, who are therefore inherently more topic-worthy than inanimate participants and thus more likely to be expressed pronominally. In (11b), there is an extra connotation of the malefactive object being affected by the situation (a change of state from being not alone to being alone).

To summarize: direct object and other head-marked objects cannot be clearly distinguished in Yurakaré on the grounds of the argument that only the latter have alternative ways of being expressed, i.e., by means of a peripheral construction.

The third criterion, verbal morphology, goes a long way, but is still problematic. As mentioned, objects are marked by personal prefixes on the verb. A number of object types are marked by additional verbal morphology, which I term "verbal case markers." Table 1 gives an overview of these verbal case markers for the six different types of objects.

The verbal case markers are prefixed to the root of the predicate and are combined with the object prefixes of (4) above, with some variations. In the verbal template, this appears as follows:

(12) Person marker (object) - Verbal case marker - Root - Person marker (subject)

As shown in table 1, the direct object and the involuntary comitative do not have any additional morphology on the verb; all the others have either a separate marker on the verb or, in the case of the voluntary comitative, a vowel change in the person prefixes. The direct object and the involuntary comitative are marked only by the person prefixes on the verb given in (4). In fact, the only difference between the direct object and the involuntary comitative is in the marker for the third-person singular, and only under certain circumstances.

7 The form sibbë is used in isolation; when it carries prefixes, it has no geminate consonant. 
TABLE 1

OVERVIEW OF OBJECTS IN YURAKARÉ

\begin{tabular}{lc}
\hline \multicolumn{1}{c}{ Name } & Verbal Case Marker \\
\hline Direct object & Unmarked \\
Malefactive & $-l a-$ \\
Goal & $-y$ - \\
Benefactive & $-n$ - \\
Involuntary comitative & Unmarked \\
Voluntary comitative & Vowel change \\
\hline
\end{tabular}

\section{(13) Direct object Involuntary comitative Value unmarked $/ \mathrm{ka}^{-} \quad \mathrm{ka}-\quad$ 3sG}

The variation in the third-person singular forms is determined by the class of the noun. Nominal class in Yurakaré is based on inherent plurality and collectivity. ${ }^{8}$ Nouns that are inherently singular and collective (e.g., bounded pieces of mass) trigger the marker $k a-$; with all other nouns, there is no overt marking, as shown in this contrastive pair:

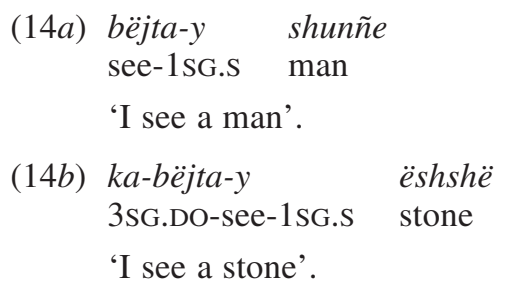

This distinction is not made for the involuntary comitative:

\begin{tabular}{|c|c|c|}
\hline$(15 a)$ & $\begin{array}{l}\text { ka-mala-y } \\
\text { 3sG.ICO-go.sG-1sG.S }\end{array}$ & $\begin{array}{l}\text { shunñe } \\
\text { man }\end{array}$ \\
\hline & 'I took a man with me & \\
\hline $15 b)$ & $\begin{array}{l}\text { ka-mala-y } \\
\text { 3sG.ICO-go.SG-1sG.S }\end{array}$ & $\begin{array}{l}\text { ëshshë } \\
\text { stone }\end{array}$ \\
\hline
\end{tabular}

Of course, one way out would be to consider a verb like mala to be ambitransitive, and the involuntary comitative not to be different from the direct object. However, there are good reasons not to do this. First, there are (albeit few) "real" ambitransitive verbs in Yurakaré, and they behave like bëjta in

\footnotetext{
${ }^{8}$ There are four nominal classes in Yurakaré: "normal" nouns that can be plural, inherently singular nouns, inherently singular collective nouns, and inherently plural collective nouns. In a great number of cases, class membership is not context-dependent, therefore, I use the term noun class. The inherently collective singular class is the only one that triggers deviant object marking in the direct object paradigm. See Van Gijn (2004) for more details.
} 
(14) when used transitively_-not like mala in (15). Second, there are a number of verbs that have stem suppletion conditioned by the number of core participants. This system functions on an ergative basis: it is sensitive to the number of the subject participant for intransitive predicates and the number of object participants for transitive predicates. The presence of a plural involuntary comitative marker on a basically intransitive stem that shows suppletion for number of participants does not trigger a plural stem; rather, the stem still functions as a basically intransitive stem, reacting to the number of the subject participant. Third, considering the direct object and involuntary comitative as constituting a single type of object ignores the semantic coherence of both object types and the functional difference that exists between them. The functional-semantic coherence of each object type is discussed below.

In the end, even though the contours of a qualitative difference between direct object and the other head-marked objects can be distinguished, it is hard to make a clear division between these two groups. In this paper, I therefore disregard this difference and instead look at the six object types as equivalent functional domains that, as argued below, together form a symmetric system of encoding different types of undergoer participants.

In what follows, I describe the forms and functions of each of the six objects, followed by an account of the whole domain of object marking in 4.3.

4.2.1. Direct object. The direct object is normally obligatorily marked on the verb by means of the person prefixes given in (4) without any further verbal morphology - but with the third person marked as indicated in (13). As mentioned above, the variation in the third-person singular forms-the only deviation from the basic paradigm given in (4) - is determined by the class of the noun.

The direct object prototypically marks the patient in an event (see examples 5 and $6 a$ ). It can also mark themes and, to a lesser extent, goals; but in general it is more rigid than the subject with regard to the semantic roles it can encode:

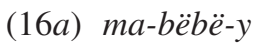

3PL.DO-search.for-1sG.S

(goal)

'I search for them'.

(16b) ma-bëjta-y

3PL.DO-see-1SG.S

(theme)

'I see them'.

4.2.2. Malefactive. The malefactive object marks a participant that is not involved in the event but is nevertheless affected by it, usually in a detrimental way. The malefactive participant is cross-referenced by means of one of the object prefixes in (4), followed by the verbal case marker $l a-.{ }^{9}$

${ }^{9}$ Some speakers, notably those who live in or come from the Chapare/Carrasco area, use

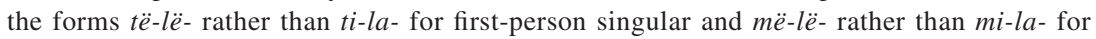


(17a) ti-la-bishmë- $\emptyset$

1sG-MAL-smoke-3.s

'He is smoking in my face'.

(17b) ti-la-mala- $\emptyset$

1SG-MAL-go.SG-3.S

'He left me (went from me)'.

(17c) ta-la-mashi- $\emptyset$

1PL-MAL-rain-3.s

'We were caught by the rain'.

A frequently observed function of this object is to mark a detrimentally affected external possessor (Payne and Barshi 1999); the possessed item may be expressed as a direct object, as in $(18 a),{ }^{10}$ or as a subject, as in $(18 b)$ :
ti-la-che-m
ti-chata
1SG-MAL-eat-2sG.s 1sG.PS-food

'You ate my food [the food that was meant for me]'.

(18b) ti-la-dyinde- $\emptyset \quad$ ti-nñu

1sG-MAL-sad-3.s 1sG.PS-baby

'My baby is sad [affecting me]'.

In all of these cases, the malefactive object is not involved directly in the event, but rather as a bystander being indirectly affected by the event.

4.2.3. Goal. Goal objects combine with movement verbs only. They are formed using the object cross-reference system given in (4), followed by the verbal case marker $-y$. The combination of $t i$ - ' $1 \mathrm{sG}$ ' or $m i$ - ' $2 \mathrm{SG}$ ' with $y$ - 'goal' yields a surface structure of $t \ddot{e}-y$ - and $m \ddot{e}-y$ - respectively, as a result of dissimilation. Goal objects denote individuated entities that serve as the target of a movement, often with the interpretation 'to get X':
(19a) ka-y-danda-ma asha $=$ chi toronja
3SG-GOA-go.up-IMP.SG
above $=$ DIR
grapefruit
'Go up to get me a grapefruit'.
(19b) ka-y-mala-ma
3SG-GOA-go.SG-IMP.SG 2sG.PS-wife
'Go and get your wife'.

\footnotetext{
second-person singular, which can be seen as vowel assimilation of both underlying vowels /i/ and /a/ to /æ/, written $\ddot{e}$. In Van Gijn (2006), I call this process "vowel leveling."

${ }^{10}$ In these cases, the possessed item is not expressed phonetically, as the third-person singular direct object is unmarked.
} 
Sometimes, the translation 'to get $\mathrm{X}$ ' does not quite work:

(20a) të-y-yира- $\emptyset$

1SG-GOA-enter.SG-3.s

'He went in for me [e.g., to talk to me]'.

(20b) pa-y-yajta-n-tu

li-massë- $p=$ chi

2PL-GOA-run;jump-DET-1PL.S DEL-stand.PL-2PL.S=DIR

'Let's run to where you guys are!'

In these latter examples, the goal of the movement is to be with or in the vicinity of the goal object, ultimately to do something with that participant.

4.2.4. Beneficiary. Beneficiary objects are formed by combining the cross-reference prefixes of (4) with the marker $n$ - (with allomorph $m$-). Beneficiary is a generalized label for this object because in addition to beneficiary (21), it also marks recipient (22) or addressee (23):
(21a) ti-n-dula- $\emptyset$
'He made me my house'.
(21b)
ti-ma-m-bëbë-ma
ti-oshewo $=w$
1SG.PS-pot $=\mathrm{PL}$
1SG-3PL.DO-BEN-search-IMP.SG
'Find me my pots'.
(22a) ti-n-wita-m
1SG-BEN-arrive.SG-2SG.S
'You came to me, arrived at my place'.
(22b) mi-m-bache-ni
2SG-BEN-send-DET:1SG.S
'I am going to send it to you.'
(23a) mi-n-dyuju-shti
2SG-BEN-inform-FUT:1SG.S
'I am going to inform you'.
(23b) ti-n-kama- $\emptyset$
1SG-BEN-call-3.S
'He is calling me'.

Verbs denoting states, processes, or achievements also often combine with this object. The benefactive object denotes a person who has some interest in the state of affairs that has arisen, also as an external possessor:
(24a) ti-n-duta- $\emptyset$ ayma
1sG-BEN-burn-3.s fire
'The fire is burning (for me), e.g., when trying to light a fire'. 


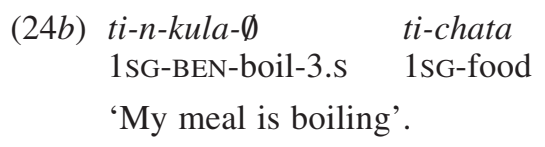

4.2.5. Involuntary comitative. The involuntary comitative object is marked only by the pronominal system in (4); it has no separate verbal case marker. Involuntary comitative objects attach to verbs denoting events that involve a change of location or state of the subject. The involuntary comitative participant in these types of events experiences the same change of state or location but—unlike the subject participant—without having any control over it:

\begin{tabular}{|c|c|c|c|}
\hline mala & 'go' & ka-mala & $\begin{array}{l}\text { 'bring/take something/ } \\
\text { someone' }\end{array}$ \\
\hline bushu & 'lie (down)' & ka-bushu & $\begin{array}{l}\text { 'lie (down) with } \\
\text { something/someone' }\end{array}$ \\
\hline dele & 'fall' & ka-dele & $\begin{array}{l}\text { 'fall with something/ } \\
\text { someone' }\end{array}$ \\
\hline shudy & 'hide (intr)' & ka-shudyujta & $\begin{array}{l}\text { 'hide with something/ } \\
\text { someone' }\end{array}$ \\
\hline
\end{tabular}

According to Kemmer (1993:206-7), events that involve a change of state or location have middle semantics: they are in between passive and active but also in between intransitive and transitive events. This latter dimension is of importance here. In Kemmer's terms, intransitive events have an initiator only (S); transitive events have an initiator (A) and an endpoint (P); middle events have an initiator and an endpoint, but they are one and the same participant and not necessarily distinguished in their different roles. The involuntary comitative is associated with the endpoint only in these constructions.

4.2.6. Voluntary comitative. The voluntary comitative object pronominal system is formally related to that given in (4), showing regular sound correspondences /i/ with /æ/, written $\ddot{e}$, and /a/ with /u/:

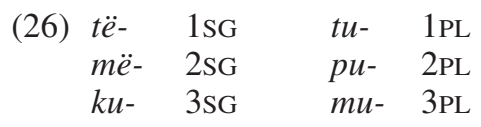

The voluntary comitative participant is actively involved in the event and "undergoes" the accompaniment or help of another participant, encoded as the subject. Consider the following examples: ${ }^{11}$
abëssë- $\emptyset$ 'he is playing'
të-bëssë- $\emptyset$ 'he is playing with me' abayla- $\emptyset$ 'he is dancing' mala- $\emptyset$ 'he goes' të-bayla- $\emptyset$ 'he is dancing with me' të-mala- $\emptyset$ 'he follows, goes with me'

${ }^{11}$ The $a$ - in abayla, abëssë, and anënë is a lexicalized incompletive marker. It is obligatorily present in the bare root but disappears when the root is combined with affixes. 


$\begin{array}{llll}\text { dula- } \emptyset & \text { 'he makes it' } & \text { të-dula- } \emptyset & \text { 'he helps me make it' } \\ \text { anёnё- } \emptyset & \text { 'he is cooking' } & \text { të-nёnё- } \emptyset & \text { 'he helps me cook' }\end{array}$

Together, the involuntary and voluntary comitative objects instantiate the comitative semantic role. Luraghi (2003:28) claims that the prototypical comitative "involves an animate agent, performing an action together with another animate individuated entity, conceived as performing the same action." This corresponds to the voluntary comitative object in Yurakaré. The involuntary comitative represents a non-prototypical form of the comitative called "accompaniment" by Luraghi.

The semantics of the two types of comitative in Yurakaré are similar to a category that has been labeled "sociative causative" (Shibatani and Pardeshi 2000), where the causer not only makes the causee execute an event but participates in it him/herself as well. Even though there are parallels to this notion, I would like to stress the fact that the causative element in constructions involving the voluntary comitative is in many cases not very clearly present, if at all.

4.3. Indirectly and directly involved objects. In this section, I argue that the six functional types of objects in Yurakaré form a symmetrical system of three functional groups: patients, goals, and comitatives, each with two variants - a directly involved participant and an indirectly involved participant (see table 2). In addition to semantic/functional considerations, table 2 is based on the fact that the distinction between directly and indirectly involved participants has a morphosyntactic reflection in the verbal template:

(28) Indirectly involved objects - Directly involved objects - Root

A verb can maximally carry two head-marked objects. The directly involved objects cannot be combined with each other, nor can the indirectly involved objects. ${ }^{12}$ Combinations of two objects consist of a directly and an indirectly involved object:

(29a) ti-ma-n-kaya-ma

1SG-3PL.DO-IO-give-IMP.SG

'Give them to me'.

(29b) ti-ja-la-mala- $\emptyset^{13}$

1SG-3SG.ICO-MAL-go.SG-3.S

'He took it away from me'.

${ }^{12} \mathrm{I}$ am aware of one counterexample where a malefactive object and a benefactive object are combined, but this example was elicited only after strong prompting.

${ }^{13}$ The consonant $/ \mathrm{k} /$ is lenited to [h], written $j$, after a vowel, so the underlying form of $j a$ - here is $k a-$. 
TABLE 2

OBJECTS IN YURAKARÉ

\begin{tabular}{lll}
\hline \hline & \multicolumn{1}{c}{ Directly Involved } & \multicolumn{1}{c}{ Indirectly Involved } \\
\hline Patient & Direct object & Malefactive object \\
Goal & Goal object & Benefactive object \\
Comitative & Involuntary comitative & Voluntary comitative \\
\hline
\end{tabular}

(29c) ku-ma-y-danda-ma

3sG.VCO-3PL-GOA-go.up-IMP.SG

'Go up with him to get them!'

The parameter of "involvement," which I argue to be the determining factor for the two vertical columns in table 2 , refers to the degree of centrality of the participant to the event: the subject participant directly acts upon a directly involved object. Indirectly involved objects are not acted upon directly: they are not involved in the event proper. Rather, they represent an alternative perspective to the state of affairs or the participants who have an interest in the state of affairs. Their morphological form indicates the nature of their perspective or interest. Moreover, directly involved participants have a greater effect on the interpretation of the predicate than indirectly involved participants.

The vertical columns in table 2 (patient vs. goal vs. comitative) show that the patient type is closest to the canonical direct object and that the goal type deviates from the patient type in lacking attainment of the object. Comitatives differ from patient type objects in the sense that their role is less distinguishable from the subject role than is the case with patients. In subject-direct object combinations, the subject is normally the agent and the direct object the patient. In subject-comitative combinations, part of the experience of the event is shared between the subject and the object. The difference between indirectly and directly involved objects can be seen as a difference in involvement. Figure 1 is a schematic representation of the different types of objects in Yurakaré.

Figure 1 should be read as follows: the leftmost object (direct object) comes closest to the canonical idea of an object-a directly involved patient. All other objects represent movements away from this canonical object: upward movement involves a decrease in distinguishability of the semantic roles of subject and object, downward a decrease in the attainment of the object participant, and rightward a decrease in involvement. Note that the degree of involvement is relative to the semantic type (patient, goal, or comitative); i.e., I do not claim that, for instance, the voluntary comitative is less involved than the goal object. Rather, within each semantic type, there is a more and a less involved participant.

I now turn to the role of verb semantics in the choice of one of these grammatical roles. 


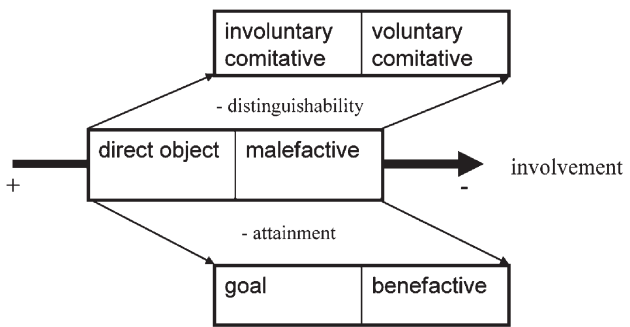

FIG. 1.-Semantic map of Yurakaré objects.

5. Verb semantics and choice of argument encoding. The publication of Hopper and Thompson's (1980) influential paper on transitivity has led many to consider transitivity as a prototypical notion that can be broken down into several contributing factors: an A participant high in potency; an $\mathrm{O}$ participant that is individuated and totally affected; an event that is an action rather than a state, which is furthermore telic, punctual, realis, etc. While Hopper and Thompson focus on alternative argument encodings for one and the same predicate, Tsunoda (1981), discussing ergative languages, relates the multifaceted nature of transitivity to different verb classes; i.e., he looks at case patterns across verb classes. Tsunoda (1981:393) coins the term "effectiveness condition" to describe a list of criteria, in the style of Hopper and Thompson (1980), that contribute to the degree of transitivity of an event. These criteria relate to the $\mathrm{A}$ argument, the $\mathrm{O}$ argument, and the event itself. On the basis of these criteria, he sets up a verb-type hierarchy (Tsunoda 1981:409):

(30) Effect $>$ Perception $>$ Pursuit $>$ Knowledge $>$ Feeling $>$ Possession

The more to the right a verb class is, the less likely it is transitive (ergative-absolutive in Tsunoda's research, but the same can be said for nominative-accusative). Tsunoda further subdivides verbs of effect-resultative (kill, break) vs. non-resultative (shoot, hit) — and perception verbs, based on attainment-attained (see, hear) vs. non-attained (look, listen).

Building on Hopper and Thompson's and in particular Tsunoda's work, Malchukov (2005) decomposes Tsunoda's Effectiveness Condition into three domains: (1) patient-related. (2) verb-related, and (3) agent-related. These three domains are reflected in Malchukov's (2005:113) semantic map of transitivity, shown in figure 2 .

Figure 2 should be read as follows: the verb classes situated toward the left are more likely to be encoded by a transitive predicate; the further to the right one goes, the more likely it is that intransitive structures will appear. Roughly three lines departing from "effective action" can be discerned. The top line, going from effective action to contact, and via pursuit to motion, represents a gradual deviation from the prototypical transitive situation in 


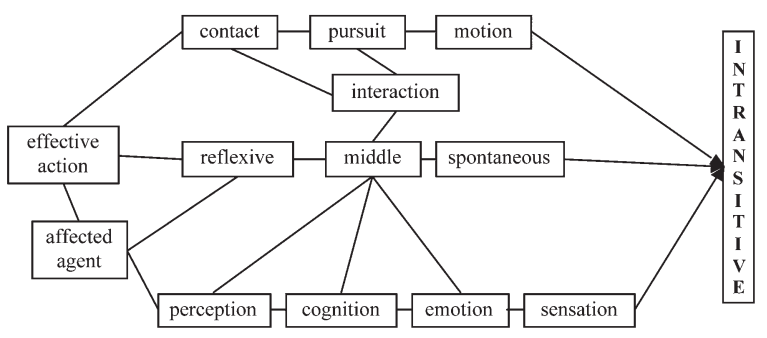

FIG. 2.-Malchukov's (2005) semantic map of factors influencing transitivity.

terms of the patienthood of the P-participant (patient/goal). The middle line (reflexive - middle - spontaneous) concerns the event itself, in terms of a decrease of distinguishability of participants, based on Kemmer's (1993) account of middle voice. The bottom line moves from affected agent to perception, cognition, emotion, and sensation verbs, and represents a gradual decrease of agentivity of the A-participant (agent/experiencer). Here, we are concerned with the top and bottom lines only. (For the middle line, all structures, from reflexive to the right, are intransitive in Yurakaré.)

5.1. Patient-related decrease in transitivity. In figure 2 , the route from effective action via contact verbs, pursuit verbs, and motion verbs highlights a decrease in patienthood of the P-participant, from patient-like objects to goal-like objects. For Yurakaré, this particular continuum tells something about the semantic limits of direct objects: at what point do we find object types that represent less prototypical undergoers, and at what point do we find peripheral (postpositionally-marked) objects?

Verbs denoting effective action, which are necessarily resultative (like 'break'), as well as contact verbs, which are not necessarily resultative (like 'touch'), are transitive in Yurakaré; their patient participants are encoded as direct objects (all verbs in the examples have a valence of two):

(31a) büsüjbü- $\emptyset$

break-3.s

'He broke it'.

(31b) ma-büsüjbü- $\emptyset$

3PL.DO-break-3.s

'He broke them'.

(31c) sisë- $\emptyset$

touch-3.s

'He touched it'. 
(31d) ma-sisë- $\emptyset$

3PL.DO-touch-3.s

'He touched them'.

There does seem to be a difference, however, between resultative and nonresultative action in that only the latter can be represented as ongoing, in which case the patient is encoded as a malefactive object: ${ }^{14}$

(32a) *ma-la-büsüjbü- $\emptyset$

(32b) ma-la-sisë- $\emptyset$

3PL-MAL:INC-touch-3.s

'He was touching them'.

On the opposite side of the top line of figure 2, motion verbs normally take dependent-marked (by means of a postposition) goal arguments:

$$
\begin{array}{ll}
\text { mala-y } & \text { lëtëmë=chi } \\
\text { go.SG-1SG.S jungle=DIR } \\
\text { 'I went to the jungle'. }
\end{array}
$$

However, motion verbs very productively take different types of objects, as these forms for mala 'to go (sg)' show:

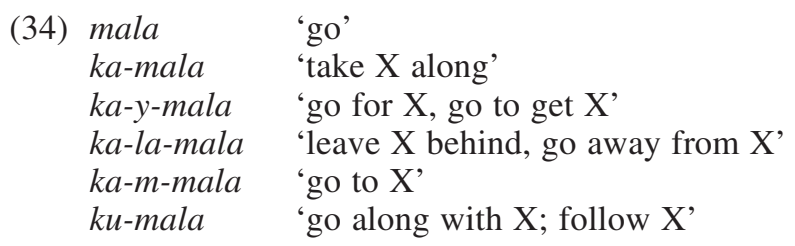

As argued in $\mathbf{4 . 3}$ above, the direct object is the most prototypical object, and the other head-marked objects deviate in different ways from this prototype. It can be said that the non-prototypical objects are semantically intermediate between direct objects and dependent-marked peripheral participants (see also the discussion at the beginning of $\mathbf{4 . 2}$ ).

For pursuit verbs on the patient-related scale in figure 2, there are mainly non-prototypical objects in Yurakare (all verbs in the examples have a valence of two):

$\begin{array}{llll}\text { Inflected } & & \text { Root } & \text { Applicative } \\ \text { Form } & \text { Translation } & \text { Meaning } & \text { Type } \\ \text { ka-n-wita } & \text { 'arrive at' } & \text { arrive } & \text { benefactive } \\ \text { ka-n-tütü } & \text { 'wait for' } & \text { be; sit } & \text { benefactive } \\ \text { ka-y-mala } & \text { 'fetch, go for' } & \text { go } & \text { goal }\end{array}$

14 The verb carries an incompletive prefix $a$-which is fused with the final vowel of the malefactive verbal case marker. 


$\begin{array}{llll}k u \text {-mala } & \text { 'follow' } & \text { go } & \text { active comitative } \\ k u \text {-yuda } & \text { 'help' } & \text { help } & \text { active comitative } \\ k a-l \text {-iche } & \text { 'pay' } & \text { have value } & \text { malefactive }\end{array}$

In (35), goal-like participants mainly invole three applied objects: benefactive objects, goal objects, and voluntary comitative objects, each referring to different goals: goal objects refer to goals that the subject intends to affect; benefactive objects are recipients or addressees in an interactional event; voluntary comitative objects are for goals that are themselves actively involved in the action. The last example in (35), kaliche, is a special case. The root ichee means 'have value, be of value'. With the malefactive object, its meaning has been conventionalized to 'pay', but I consider the literal translation to be 'to have value from someone', which explains the appearance of the malefactive object with a source meaning.

There are also verbs that take non-applied objects in this class, but they constitute a minority:

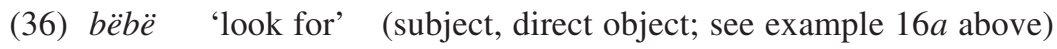

The general picture for the patient-related line in figure 2 is a gradual decrease in transitivity, moving from left to right: resultative and non-resultative contact verbs have regular (i.e. involving a direct object) transitive case frames, and we find malefactive objects in incomplete non-resultative events. Further to the right, pursuit verbs generally take less canonical objects, such as benefactive, goal, or voluntary comitative objects; and motion verbs have dependentmarked goals (even though applied objects may also appear here for animate and/or highly topical participants). This distribution underlines the fact that each non-canonical object highlights a different semantic movement away from the prototypical patient, without giving up the general binding element between head-marked objects—salient affectedness-much in line with the semantic characterizations given in figure 1 .

5.2. Agent-related decrease in transitivity. The bottom line of figure 2 highlights a gradual decrease in prototypical agent features on the part of the A-participant, defined semantically as agent/experiencer. Some languages have a non-canonically encoded subject with verbs denoting actions like 'eating' and 'drinking'. According to Naess (2000), this is because in such an event, the agent may be controlling but s/he is also affected by the act of ingestion. Nevertheless, in Yurakaré, ingestion verbs have a canonical transitive (subject-direct object) case frame:

(37a) ma-che-shti

3PL.DO-eat-FUT:1SG.S

'I will eat them'. 
(37b) ma-ense-shti

3PL.DO-drink-FUT:1sG.S

'I will drink them'.

Perception verbs form an interesting class in terms of argument encoding in Yurakaré, because within this semantic class the canonical transitive case frame seems to break down. A number of verbs have a canonical transitive case frame:

(38a) ma-bëjta-y

3PL.DO-See-1SG.S

'I see them'.

(38b) ma-ujwa-shti

3PL.DO-look.at-FUT.1SG.S

'I will look at them'.

A perception verb with a less specific meaning is wëshë 'sense', which can refer to hearing, understanding, realizing, physically feeling, rememberingdepending on the affixes it takes and/or the case frame (presented in order of frequency of occurrence):

$$
\begin{aligned}
& \text { (39a) mi-la-wshë } \ddot{e}^{15}-y \\
& \text { 2sG-MAL-sense-1sG.S } \\
& \text { 'I heard you'. } \\
& \text { (39b) wëshë-të-y } \\
& \text { sense-MID-1SG.S } \\
& \text { 'I realized, understood'. } \\
& \text { (39c) ti-wëshë- } \emptyset \text { sobbo } \\
& \text { 1sG.DO-sense }{ }^{16} \text {-3.s worm } \\
& \text { 'I felt a worm on my body'. }
\end{aligned}
$$

Since the canonical transitive case frame starts to break down within the group of perception verbs, one would expect to find more examples of non-canonical case marking in cognition verbs, and this is indeed the case. The most general cognition verb, meaning 'to know', takes an involuntary comitative object: ${ }^{17}$

15 The first vowel of wëshë is elided in certain circumstances.

16 The morphological and semantic structure of the predicate here is unclear. It may be that wëshë is ambitransitive or has a zero causative derivation. Moreover, this construction is not accepted by every speaker.

17 This predicate stems from the monovalent predicate ayle 'to be tamed, familiarized (animals)'. The same predicate is also used to express the process of adapting to one's surroundings (with the same case frame as 'knowing'). 


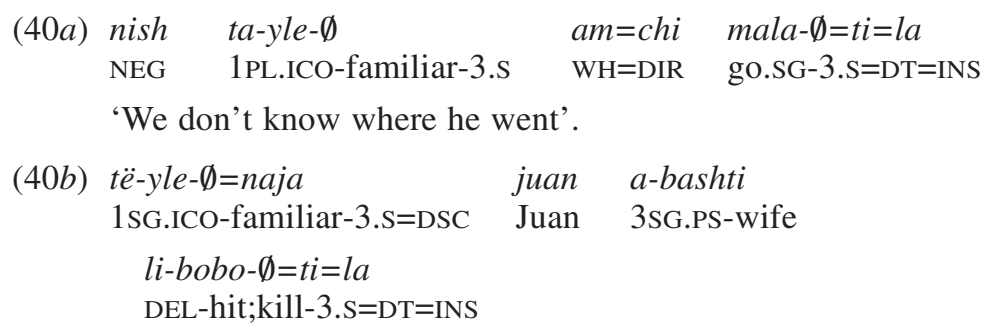

'I know that Juan killed his wife'.

While the "knower" is encoded as an involuntary comitative object, the thing known carries an instrument postposition. This means that the proposition that is known cannot be the subject on the predicate expressing 'to know'; and the subject, if present at all, is impersonal. However, in the following construction, the predicate does seem to have a personal subject:

$\begin{array}{lll}\text { (41) nish } \quad \text { të-yle- } \emptyset & \text { ati } & \text { kwento } \\ \text { NEG } 1 \text { sG-familiar-3.s } & \text { DEM } & \text { story } \\ \text { 'I don't know that story'. } & \end{array}$

The subject status of ati kwento in a construction like (41) is corroborated by the fact that in a similar construction with a plural subject, it triggers audible subject agreement on the verb (data from NTM [n.d.:lesson 40]):

(42) tëtë $\quad k a n t a=w=j a \quad$ pa-yle- $\emptyset=w$

what $\quad$ song $=\mathrm{PL}=\mathrm{TH} \quad 2 \mathrm{PL}-$ familiarized-3. $\mathrm{S}=\mathrm{PL}$

'What songs do you guys know?'

In short, the concept of knowing something is presented as a passive process, the experience of a change of state as the result of knowledge becoming familiar.

Another cognition verb with an experiencer that is not encoded as a subject is sheta, meaning 'to be lost'; but with a malefactive object, it means 'to forget':

$$
\begin{array}{lll}
l i-t i-l a-\text { sheta- } \emptyset=\text { naja } & n a & t i-n-\text { dyuju- } m=t i \\
\text { DEL-1sG-MAL-lost-3.S=DSC } & \text { DEM } & \text { 1sG-BEN-tell-2SG=DT } \\
\text { 'I forgot what you told me'. } &
\end{array}
$$

Given the meaning of sheta, we can follow with more precision the logic of the language. Sheta literally means 'something is lost'. The prefix $l i-$, obligatory in this reading of the verb, often appears with processes that manifest themselves internally in a person: 'something that is internally lost'. The subject participant is arguably empty, since clauses marked with $=t i$ ' different perspective' normally encode coordinate, temporal, or conditional clauses. The literal translation of (43) is probably 'it was lost to me when you told me'. 
The verb for 'to realize' or 'to be aware, attentive' is wëshë-të, which takes a subject experiencer. However, the verb is morphologically complex: it has the root wëshë, which has been discussed above, plus a suffix -të that normally indicates middle voice.

(44) nish wëshë-të- $\emptyset=w=n a j a$

NEG sense-MID-3.S=PL=DSC

'They are not aware of a thing anymore'.

Middle voice in Yurakaré extends to reflexives, reciprocals, passives, and spontaneous events. Wëshë-të can be said to be the reflexive counterpart of wëshë: 'to sense oneself', which gives a passive, undergoing element to the experience.

A true subject experiencer is found in the verb kuymaluma 'think', a morphologically complex verb consisting of an invariant third-person singular voluntary comitative object and a combination of a distributive marker -uma and a marker of bounded (collectivized) multiple events $i$-, which together indicate that the event is seen as a single event although it in fact takes place at multiple points in time and/or space. The root mala means 'to go'. The literal translation of this complex verb is 'to walk around with it' or 'to follow it around', where 'it' refers to a thought or a worry. That the root for 'to think' is linked to the root for 'to go' is corroborated by the fact that the suppletive stem for plurality (bali for plural) is maintained. ${ }^{18}$

$$
\begin{aligned}
& \begin{array}{lll}
\text { ati } & k u-y-m a l-u m a-y=j a & \text { kereyenti } \\
\text { DEM } & \text { 3sG.VCO-BND-go.SG-DST-1SG.S=ST } & \text { believer }
\end{array} \\
& \text { shinama }=\text { se } \\
& \text { now }=\text { CNTR }
\end{aligned}
$$

'I thought about that, and now I am a believer!'

$$
\begin{aligned}
& \text { (45b) ottu=ja tütu=ja ku-i-bali-wma- } \emptyset=w \\
& \text { go.out:3PL=ST sit:3PL=ST 3sG.VCO-BND-go.PL-DST-3.S=PL }
\end{aligned}
$$

The subject experiencer for 'to think' can be explained by diachronic analysis of the predicate kuymaluma, which stems from an action verb mala. Thinking is a more active and controlled activity than knowing or forgetting (one can stop thinking but not knowing or forgetting). Realizing something has both an active (to pay attention) and a passive (becoming aware) component, pertaining to the same participant.

${ }^{18}$ As Yurakaré tends to avoid consonant clusters, suffixes that begin with a vowel and prefixes that end in a vowel may provoke morphophonological changes when combined with a V-final or $\mathrm{V}$-initial root, leading either to elision, as in kuymal(a)uma, or to a change of one of the vowels into a coda- or onset-glide, as in, e.g., kuybaliwmaw. 
Emotion verbs show inconsistent case frames. Some of them take nonsubject experiencers (46); others take subject experiencers (47):

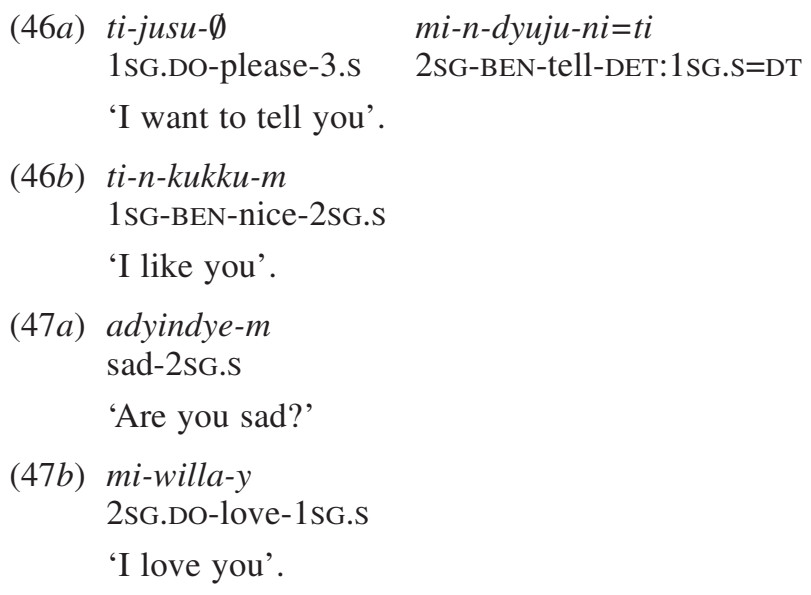

The predicate kusu in (46a) takes a direct object experiencer and an impersonal subject, referring to a situation rather than a participant: 'It pleases me when I would tell you'. The predicate $k u k k u$ in (46b) means '(be) nice' and refers to an attribute of the stimulus. The experiencer is the beneficiary of that attribute. The constructions in (46) are parallel to the examples in (24), with a beneficiary experiencer of a state.

The fact that the experiencer of the state adyindye '(be) sad' is encoded as a subject has to do with the fact that this state does not exist outside of this participant, i.e., it does not pertain to the situation or another participant. The predicate root wilala, shortened to willa for reasons of stress, also refers to an emotion of the experiencer rather than a property of the stimulus. This difference and the consequences it has for argument encoding can be illustrated by the pair ñole 'desire', ñolele 'be desirable', which take opposite argument structures:

(48a) mi-la-ñole-y

2sG-MAL-desire-1sG.S

'I desire you'.

(48b) ti-la-ñole le-m

1SG-MAL-desire ADJ-2SG.S

'I desire you'.

In $(48 b)$, the state of affairs is construed in such a way that desirability is a property of the stimulus, whereas in $(48 a)$, it is construed as an emotion pertaining to the experiencer. This is corroborated by the fact that nole can occur with imperative and prohibitive morphology, whereas nolele cannot (because a property cannot be prohibited): 
(49a) ma-la-ñole-yu

3PL-MAL-desire-PROH

'Do not desire them!'

(49b) *tilañoleleyu

In terms of the semantics of different objects in Yurakaré, in (48a), the stimulus is the external patient of an emotion of the experiencer, whereas in (48b), the experiencer is the external patient of a property of the stimulus.

This semantic logic is also found in other emotion verbs:

(50) të-benebene- $\emptyset$

1sG.VCO-be.unfortunate-3.s

'I feel sorry for him' (lit., 'He is unfortunate together with me'.)

In (50), the experiencer is encoded as a voluntary comitative object-a person who is involved in the state of affairs in the same way as the subject. In this case, the subject is unfortunate, and the experiencer experiences the same feeling in a secondary way.

There are two types of sensation predicates. With sensations caused by circumstances of the situation, the experiencer is encoded as a voluntary comitative (51). With sensations internal to the experiencer, $\mathrm{s} /$ he is encoded as a possessor of a noun in predicate position (52):

(51a) të-dyummë- $\emptyset$

1sG.VCO-cold(ness)-3.s

'I am cold' (lit., 'It is cold with me'.)

(51b) të-shujuta- $\emptyset$

1sG.vCO-hot(ness)-3.s

'I am hot' (lit., 'It is hot with me'.)

(52a) ti-samti

1SG.PS-thirst

'I am thirsty' (lit., 'My thirst exists'.)

(52b) a-teshti

3sG.PS-sleepiness

'He is sleepy' (lit., 'His sleepiness exists'.)

The lexical items in (51) and (52) are nominal, or at least they can be used nominally. Nouns in Yurakaré can be used as predicates without additional marking; the difference between the forms in (51) and (52) is that in the latter case the forms are morphologically still nominal although they are in predicate position, whereas the forms in (51) are morphologically predicative (they take verbal morphology). 
For the agent-scale, although there is no clear break between two verb classes, there is a steady decrease in marking the agent/experiencer as a subject as we go down the semantic map in figure 2 . The linking of agent/experiencer function to the subject grammatical role begins to break down with perception verbs, and breaks down further with knowledge verbs. Whereas perception verbs predominantly have subject experiencers, this is not the case for cognition verbs. This pattern, broadly speaking, carries through in verbs of emotion and sensation. In my view, the most important transitivity parameter (present in both Tsunoda's effectiveness condition and Hopper and Thompson's transitivity parameters) is action versus state. Tsunoda (1981:396) mentions that particular events expressing knowledge and feelings are expressed by adjectives, which corresponds to their static nature. In Yurakaré, feelings and knowledge are expressed by means of attributive words (the distinction between verbs and adjectives in Yurakaré is not very clear), and these attributes often (but not always) pertain to the stimulus or the general situational context rather than the experiencer, and the experiencer is consequently encoded as the receiver/undergoer/comitative of that attribute. Sensation predicates are even more static in Yurakaré, as they may be expressed by nominal elements, which can take a possessor experiencer.

6. Conclusion. With respect to the ideas discussed in $\mathbf{3}$ above, the following conclusions can be drawn.

(1) Syntactic roles define regions in conceptual space that represent semantically related groupings of participant roles in events (Croft 2001). Each morphosyntactically differentiated argument type (subject and the six types of object) has a coherent semantic basis, each covering a different field.

(2) A decrease in affectedness on the part of $\mathrm{O}$ leads to agent-like intransitives, and a reduction in agentivity on the part of A leads to patient-like intransitives (Malchukov 2005). Verb semantics determine the choice of case frame in that predicates that select for less prototypical patients and/or agents tend to have less prototypical case frames.

(3) In assigning a grammatical role, a language can give prominence to characteristics of participants (person prominence) or to the semantics of the relation between the verb and a participant (relation prominence) (Lehmann, Shin, and Verhoeven 2000). Yurakaré is a relation-prominent language in the sense that there are many constructions where a participant higher on the animacy scale is encoded in a lower syntactic role. More generally, the distinction between head-marked and dependent-marked participants does seem to be sensitive to participant features.

In short, the choice of argument encoding in Yurakaré depends largely on three semantic factors: $(a)$ the semantics of the grammatical role, $(b)$ the semantics of the verb, and $(c)$ the semantics of the relation between the verb and a participant. 


\section{REFERENCES}

AdAm, LuCIEN. 1893. Principes et dictionnaire de la langue Yuracare ou Yurujure. Paris: Maisonneuve.

Blake, Barry J. 2001. Case. 2nd ed. Cambridge: Cambridge University Press.

ButT, Miriam. 2006. Theories of Case. Cambridge: Cambridge University Press.

Croft, William. 2001. Radical Construction Grammar. Oxford: Oxford University Press.

$\rightarrow$ Dowty, DAvid R. 1991. Thematic proto-roles and argument selection. Language 67:547-619.

Greenberg, JosePh H. 1987. Language in the Americas. Stanford, Calif.: Stanford University Press.

$\rightarrow$ Hopper, Paul J., And Sandra A. Thompson. 1980. Transitivity in grammar and discourse. Language 56: 251-99.

Kemmer, Suzanne. 1993. The Middle Voice. Amsterdam and Philadelphia: John Benjamins.

Kuno, Susumo. 1976. Subject, theme, and the speaker's empathy: A reexamination of relativization phenomena. Subject and Topic, ed. C. N. Li, pp. 137-53. New York: Academic Press.

Lassinger, Fulgencio. 1915. El idioma yuracarés. Archivo de la Comisaría Franciscana de Bolivia, año VII, pp. 47-49, 117-19, 158-59, 204-5, 234-36, 400-401.

Lehmann, Christian; Yong-Min Shin; and Elisabeth Verhoeven. 2000. Person Prominence and Relation Prominence. Munich: Lincom Europa.

Luraghi, Silvia. 2003. On the Meaning of Prepositions and Cases. Amsterdam and Philadelphia: John Benjamins.

Malchukov, ANDREJ. 2005. Case pattern splits, verb types and construction competition. Competition and Variation in Natural Languages: The Case for Case, ed. Mengistu Amberber and Helen de Hoop, pp. 73-118. Oxford and New York: Elsevier.

NAess, AshiLD. 2000. Transitivity: From semantics to structure. Ph.D. dissertation, University of Nijmegen.

New Tribes Mission. 1991. Diccionario Yuracare-Castellano, Castellano-Yuracare. Ms., New Tribes Mission, Cochabamba.

n.d. [Forty lessons of Yurakaré]. Ms., New Tribes Mission, Bolivia.

PaYne, Doris, And Immanuel Barshi, eds. 1999. External Possession: What, Where, How, and Why? Amsterdam and Philadelphia: John Benjamins.

Petersen, David A. 2007. Applicative Constructions. Oxford: Oxford University Press.

Ribera, Julio; Asencio Rocha; ANd Walter Rivero. 1991. Vocabulario Yuracare-Castellano, Castellano-Yuracare. 3 vols. Trinidad, Bolivia: Eparu/Misereor.

Shibatani, Masayoshi, and Prashant Pardeshi. 2000. The causative continuum. The Grammar of Causation and Interpersonal Manipulation, ed. Masayoshi Shibatani, pp. 136-77. Amsterdam and Philadelphia: John Benjamins.

SuÁreZ, JoRge A. 1974. Macro-Pano-Tacanan. IJAL 37:137-54.

SwAdESH, MorRIs. 1962. Afinedades de las lenguas amerindias Akten des 34. Amerikanistenkongresses, pp. 729-38. Vienna: Fred Berger.

$\rightarrow$ TsUnODA, TASAKU. 1981. Split case-marking patterns in verb-types and tense-aspect-mood. Linguistics 19:389-438.

VAN GIJN, RIK. 2004. Number marking in the Yurakaré noun phrase. Linguistics in the Netherlands 2004, ed. Leonie Cornips and Jenny Doetjes, pp. 69-79. Amsterdam and Philadelphia: John Benjamins.

2005. Head marking and dependent marking of case relations in Yurakaré. Competition and Variation in Natural Languages: The Case for Case, ed. Mengistu Amberber and Helen de Hoop, pp. 41-72. Oxford and New York: Elsevier. . 2006. A grammar of Yurakaré. Ph.D. dissertation, Radboud University Nijmegen. 